\title{
INCREASING THE MOTOR ACTIVITY FOR PREVENTION OF SPINAL DEFORMITIES IN CHILDREN'S OF PRE-SCHOOL AGE
}

\author{
R. Paskaleva*, V. Ivanova, V. Pavlova \\ Department of Medical Rehabilitation and Ergotherapy, Physical Medicine and Sports, \\ Medical Faculty, Trakia University, Stara Zagora, Bulgaria
}

\begin{abstract}
Early diagnostics, regular monitoring, treatment, and the correct motor regimen contribute to the favorable result of disturbed posture in pre-school children. A good organization of the healing and rehabilitation measures are of prime importance including complex rehabilitation and swimming as well as the regular monitoring of the treatment results to prevent gross spinal and thoracic deformities (GC) with subsequent complications leading to severe disability. The aim of the present study is early diagnostic and increased motor activity of children of 5-6 years of age with disturbed posture in the kindergartens on the territory of the town of Stara Zagora. The subject of the study are 1483 pre-school children aged 5-6 in the kindergartens on the territory of the town of Stara Zagora. Of these, 970 children have disturbed posture, 180 children are overweight, expressed to varying degrees, and without problems and 333 children are with good physical development, corresponding to the age. The analysis of the most common types of spinal deformities was the basis for compiling and implementing a program to increase the motor activity of children.

Through regular use of kinesitherapy, swimming and sports games improves the tone of the spinal muscles, overcomes muscle imbalance and stimulates the movement of the chest. A healthy muscular corset is created and the psychic development of the children is stimulated.
\end{abstract}

Key words: early diagnostic, prevention, spinal deformities, motor activity.

The causes of spinal deformities may be of a different nature. Often they are the result of polytheological suffering or as a result of metabolic disorders after rickets (1). Contemporary lifestyle and reduced motor activity provoke the appearance of irregular posture and various deformations of the spine and chest (2).

The physical development of children and adolescents is in correlation with their motor regime and diet, with their constitution, early detection, prophylactic and treatment of acute and chronic diseases accompanying growth (3, 4). Spinal deformities are among the most prevalent diseases in childhood and adolescence (5). Contemporary lifestyle and reduced motor activity are factors that provoke the emergence of irregular posture and various

\footnotetext{
*Correspondence to: Associate Professor Ruska PASKALEVA, Ph.D., Department: Medical

Rehabilitation and Ergotherapy, Physical Medicine and Sports. Faculty of Medicine, Trakia University

11 Armeiska Str.,6003 Stara Zagora,

e-mail:ruska64@abv.bg
}

deformities of the spine and thorax in preschool children (6).

Early diagnosis, systemic monitoring, treatment, and the proper motor regime contribute to the favorable outcome of disturbed pre-school posture in children (2). It the good organization of the healing and rehabilitation activities are of prime importance, including complex rehabilitation and swimming as well as the regular follow-up of the treatment results to prevent gross spinal and thoracic deformities with subsequent complications, leading to severe disability (7, $8)$.

The most common spinal deformities in children and adolescents are habitual scoliosis. They are progressing and have an unfavorable evolution (9). Scoliosis formation is a complicated pathological process. The first manifestation is lateral deviation of the spine (S). In a functional curve, it is only justified in changing the shape of the intervertebral discs within the limits of the physiological capabilities of the spine (10). This scoliosis is 
reversible in most cases and is considered as the result of static-dynamic disorders. Signs of scoliosis begin in early childhood, may develop during growth and become permanent if not treated. These occur in children aged 5 to 6 years but the spinal curve is labile, decreasing in pelvic position and corrected for mobilization of the musculature (11). An in-depth postural evaluation is required to check if the problems are related to the lower extremities, pelvis, shoulder belt, torso, upper limbs, or functional reasons only $(12,13)$.

Several authors identify six major factors determining the anomalies of spine and chest growth and deformities. These are: the genetic factors determining the growth and development of the locomotory system; hormonal and metabolic dysfunctions affecting calciumphosphate metabolism; biomechanical factors due to decreased motor activity; environmental factors and lifestyle related to children's eating habits; abnormal skeletal growth and congenital abnormalities associated with the nervous system. Modern NMR studies of children with vertebral distortions confirm this thesis (14).

Prolonged and early rehabilitation in children with vertebral distortions is a major factor in the overall strengthening, proper development and stimulation of the whole organism (15). This leads to overcoming spinal problems, improving the function of the lungs and the chest and creating a strong muscle corset (2).

The basic principles defining the correct approach to correcting the impaired posture and overcoming the spinal deformities are limited to: maintaining the motor activity of all the structures of the spine - intervertebral discs, joints, ligament apparatus and muscles; overcoming muscle imbalance because hypertonic muscles interfere flexibility and the hypotonic ones interfere the spine stability; overcoming ligament abnormalities associated with bone growth and stimulation of postural control, nervous system and equilibrium reactions $(16,11)$.

The aim of the present study is early diagnosis and increased motor activity of children with disturbed posture at the age of 5-6 years in the kindergartens on the territory of the town of Stara Zagora.

\section{MATERIAL AND METHODS}

The subject of the study is 1483 pre-school children aged 5-6 years in the kindergartens on the territory of the town of Stara Zagora. 970 of these children have impaired posture, 180 children are overweight, expressed to varying degrees, while 333 children have no problems and have a good physical development, corresponding to their age. The analysis of the most common types of spinal deformities was the basis for compiling and implementing a program to increase the motor activity of children.

Individually, for each child, a parental informed consent was given for the study.

\section{Methodology of the research}

- Diagnosis of spinal deformities was performed with a specially designed Early Diagnostic Card, adapted to the age of the children, corresponding to their physical development, and Ott and Schober tests were modified for 5-6 years old children compared to the height.

- Overweight children were also tested on innovative methodology, according to the physical development and compared with height and weight, individual characteristics and eating habits.

- A survey was carried out on the parents of all children with impaired posture and overweight about motor activity and eating habits.

- Statistical methods for processing the results were applied. Descriptive statistics of quality variables with relative shares and $95 \%$ confidence intervals. Graphical analysis. A level of significance $\mathrm{P}<0.05$ was used in all tests.

Organization of the experimental program:

The diagnosis of the children was carried out within three months by the project team together with the students of specialty Medical Rehabilitation and Ergotherapy during the clinical practice. Work groups of students and teachers were set up to carry out the diagnosis of children. The surveys were carried out in the period October - December 2017. The beginning of the experimental program is directly related to the beginning of the students' academic year when the initial measurement of all children was performed.

Kinesitherapy experimental methods are about to be applied for correction of impaired posture by increasing motor activity and stimulating postural stability using large therapeutic ball at three kindergartens selected by certain criteria.

\section{RESULTS AND DISCUSSION}

The preschool children aged 5-6 in kindergartens are a total of 2072 on the territory of the town of Stara Zagora there. A survey and examination of the mobility of the spine and chest of the 1483 children, which is $73 \%$ of the total number of children, was carried out, the sample is representative and reliable (Figure 1). The largest share of the examined children (75-80\%) is in six kindergartens (№7, №25, №3, №23, №10, №8), and the lowest is less than 50\% in SG №11. This is a proof of the good scale of the study. 
PASKALEVA R., et al.

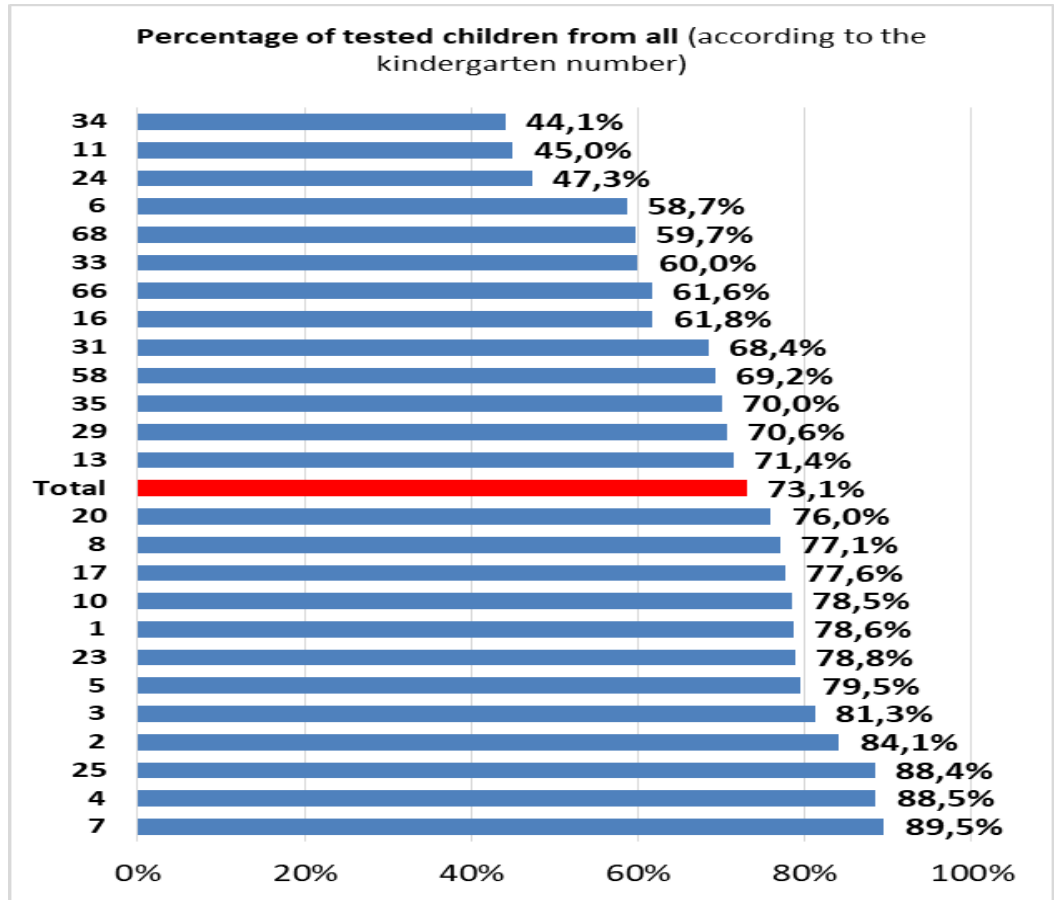

Figure 1. Percentage of children surveyed in individual kindergartens

The total percentage of children with postural disorder is $65.41 \%$ with $95 \%$ CI $(62.91 ; 67.83)$, confidence interval. Kindergartens with numbers 6, 24, 29 and 34 have statistically significantly higher percentages of children with impaired posture $(\mathrm{P}<0.05)$. Kindergartens with numbers 5 , 35 and 66 have statistically significantly lower percentages of children with impaired posture $(\mathrm{P}$ $<0.05)$.

The disturbed posture is an incorrect position of the body caused by various causes, most often as a result of weak musculature, changes in various parts of the locomotory system and the nervous system (14). The poor posture is characterized by the weakness of the whole body, especially the muscular system, a disturbance of the static position of the spine and other parts of the locomotory system (17). The motor and sensor systems involved in the posture stability pass through a transition period of 4-6 years to maturity at the age of 7-10 years. Rapid growth from childhood to adolescence occurs at the age of 9-12 years and can cause enormous changes in the position, shape and size of the spine, muscle strength and flexibility that affect postural instability (18).

Spinal deformities have been observed in structural and functional disorders of the cardiorespiratory and locomotor system due to narrow and asymmetrical chest (2). These changes lead to reduced physical activity at preschool age, depression and back pain in schoolaged children, fatigue and decreased working capacity in adults $(19,20,21)$.

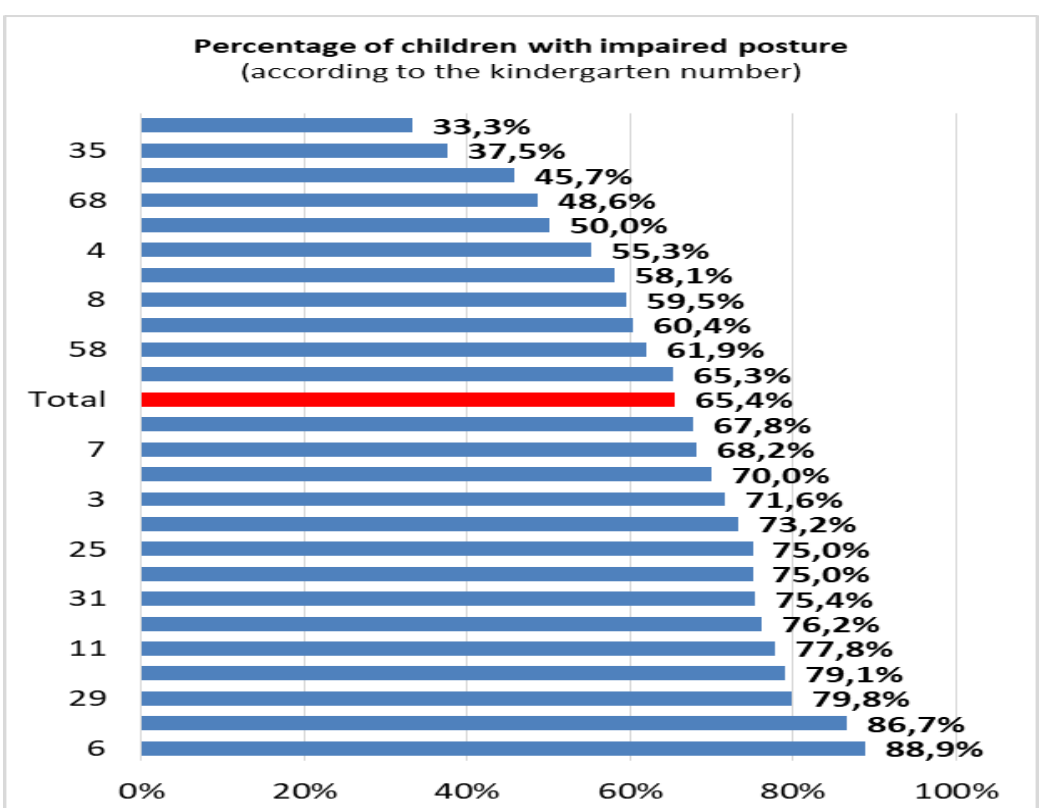

Figure 2. Percentage ratio of tested children with disturbed posture to the total number

Trakia Journal of Sciences, Vol. 16, Suppl. 1, 2018 
The results of the studies (Figure 2) are an indicator of the wide spread of the postural disorder among children aged 6-7 years. This
PASKALEVA R., et al. is $65 \%$ of all children surveyed. It confirms the thesis of the insufficient motor activity of the children in kindergartens and the family.

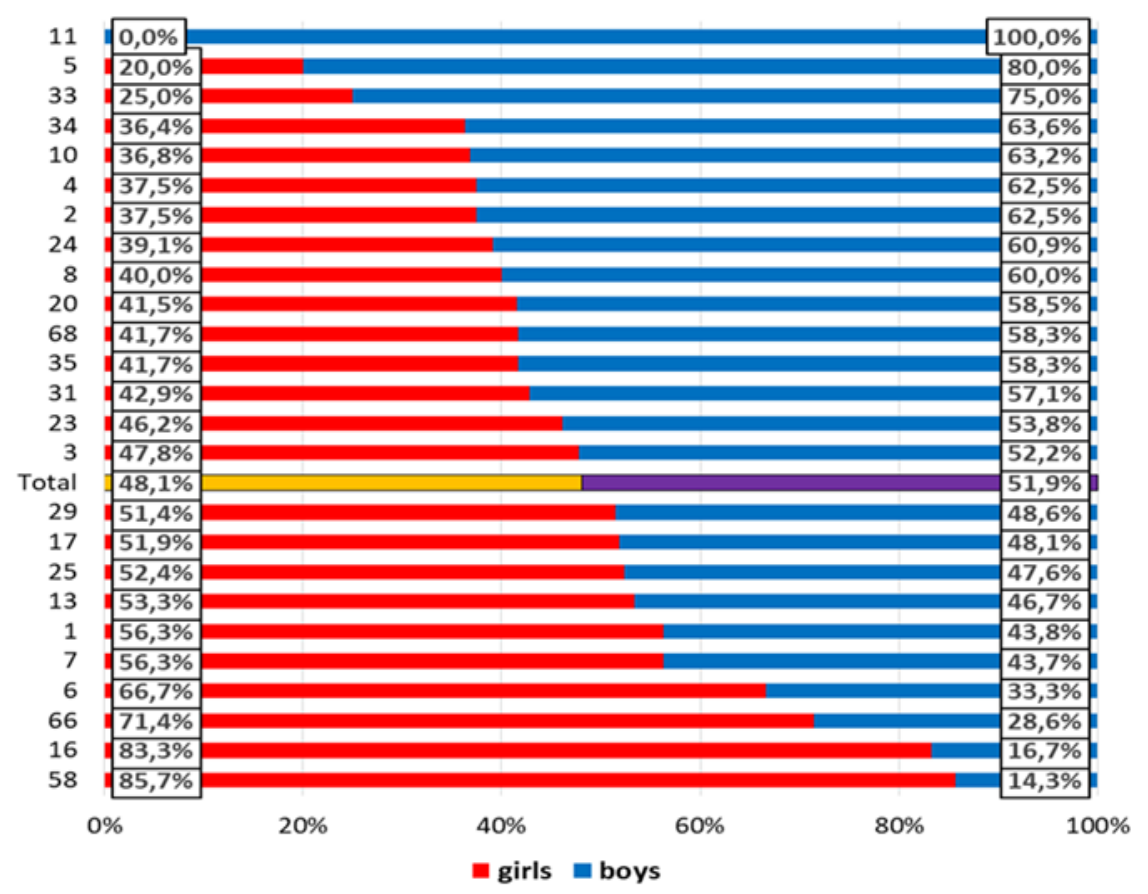

Figure 3. Percentage ratio of children with disturbed posture by gender

The number of boy divided by gender (Figure 3) with disturbed posture predominates with a small predominance of $2 \%$. This is the result of more active participation of girls in various sports and dance classes outside kindergartens.
Parental surveys show that lifestyle has a direct impact on children's lives, as parents can guide children to physical activities (7) and stimulate them to live more actively.

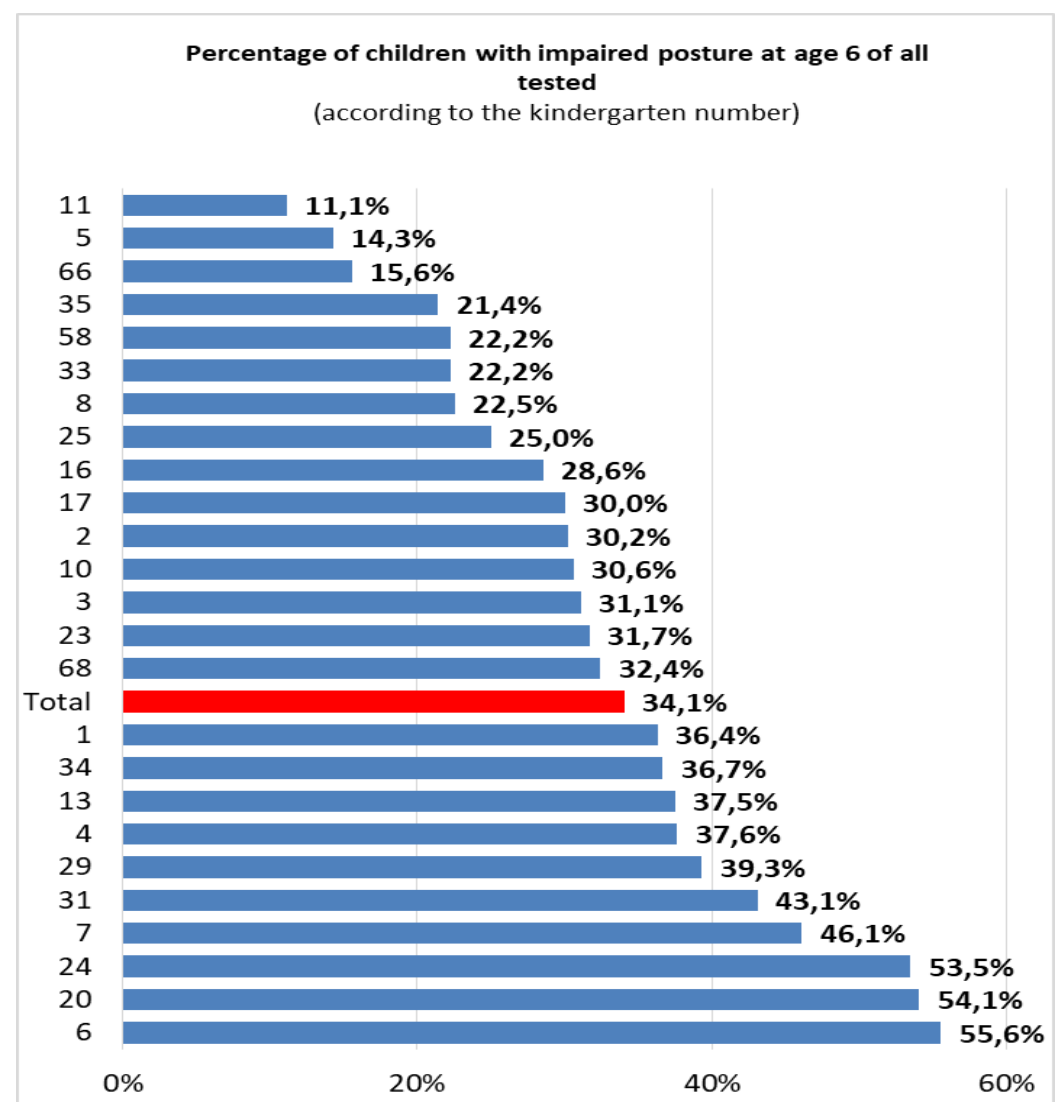

Figure 4. Percentage ratio of the children aged 6 years with disturbed posture to the total number 
Diagnostic results of children with disturbed posture aged 6 years to the total number indicate that they are $34 \%$. The remaining $31 \%$ are children aged 5 years. The difference between the two age groups of the five- and six-year-olds is minimal. This is an indication that the initial changes of the disturbed posture begin at pre-school age, which if not corrected during this period will leave lasting changes in the development of the bone system and the whole locomotor apparatus.

Parental surveys show that lifestyle has a direct impact on children's lives, as parents can guide children to physical activities (7) and stimulate them to live more actively.

Therefore, it is necessary to emphasize the need for regular and systematic participation of preschool children in preventive programs for the diagnosis and prevention of vertebral distortions conducted annually in order to prevent later onset orthostatic disorders (22, 23). There is a need for continuous cooperation between teachers in the kindergartens and the public to increase the participation of children in various forms of sport, relaxation and various types of motor activities $(24,25,26)$. Through regular use of kinesitherapy, swimming and sports games the tone of the spinal muscles improves, the muscle imbalance is overcome and the movement of the chest is stimulated. A healthy muscular corset is created and the nerve-psychic development of the children is stimulated.

\section{CONCLUSIONS}

- 1483 children were examined in kindergartens on the territory of the town of Stara Zagora, out of the total number of 2072 children. The representative sample includes $73 \%$ of all children.

- Out of all examined children, 970 (65\%) have a disorder, 180 (12\%) are overweight, and 333 (23\%) children are without problems.

- In the case of children with disturbed posture selected by gender the boys have a slight predominance (2\%), and by age, the children aged 6 have a slight predominance $(4 \%)$.

The high frequency of disturbed posture among preschool children is not only a public concern but also a public health problem for wider preventive measures to improve the motor activity of children.

\section{REFERENCES}

1. Paskaleva R., Innovative Elements in Kinesitherapy Training, Art-Therapy and Ergotherapy for Students Rehabilitation Therapists, Monograph, Publishing House EKS-PRESS - Gabrovo, p. 120, 2012.

2. Paskaleva R. Diagnosis and rehabilitation of spinal deformities - new approach in practical training. Medicine \& Science in Sports \& Exerciseq Issue 12 (2), (December), Volume 49. Lippincott Williams \& Wilkins Ltd., Pages 2855-2861, 2017.

3. Karaneshev, G., Sokolov B., Venera L. Theory and methods of healing gymnastics.Eedited by Ass.Prof. G.Karaneshev. - Sofia: Medicine and Physical Education, p.308, 1987.

4. Karaneshev, G., Sokolov B., Venova L. Guide to Practical Exercises in Remedial Gymnastics. - Sofia: Medicine and Physical Education, 182 p., 1991.

5. Paskaleva R. Kinesitherapy in common childhood diseases and relaxation techniques. Textbook. Publishing house: EKS-PRESS Gabrovo; p.227, 2015.

6. Ilieva I, R. Paskaleva. Physical activity motivating effect of kinesitherapy in schools. "Student Team Practice for the Prevention of Metabolic Syndrome", Academic Publishing - TrU Stara Zagora; pp.108-111, pp.231-240, 2010.

7. Melo K., S. Bandeira de Barros, T. Santos, A. De Marco, V. Hirota, C. Amorim de Sa. The Relationship between Family Lifestyle and Physical Activity of Children from 4 to 6 Years. International Journal of Sports and Physical Education (IJSPE) Volume 3, Issue 4, PP 12-16, 2017.

8. Koleva I., Fundamentals of Rehabilitation (with algorithms for socially significant diseases and injuries of the nervous system and musculoskeletal apparatus), Textbook. - Sofia, p.264, 2010.

9. Woggon A. D. Martinez Chiropractic treatment of idiopathic scoliosis with the CLEAR Institute method: a description of the protocol. Scoliosis; 8(Suppl 2): P6. 2013.

10.Beckner D., Ca. Beresoski2, M. Camargo, K. Fernandes, C. Siqueira, D. Fujisawa. Early signs of scoliosis in preschool childre. Fisioter Pesq.;22(1):69-75, 2015.

11.Filkova S. Prophylaxis of spinal distortion in pre-school children. Author of the dissertation thesis for awarding educational and scientific degree $\mathrm{PhD}$, Varna, p.78, 2017.

12.Filkova, S. Metodics for the prevention of spinal distortions in pre-school children. 
Collection of papers from the International Scientific Conference "European Standards in Sports Education", held in Veliko Tarnovo University "St. St. Cyril and Methodius ". Vratsa, pp. 419-425, 2013.

13.Bogdanović Z., F. Mavrić, A. Mavrić. Effects of a Programmed Corrective Training on Postural Disorders in Lumbar and Thoracic Region. International Journal of Sports and Physical Education (IJSPE) Volume 3, Issue 1, PP 7-13, 2017.

14. Winnie C. W. Chu, Darshana D. Rasalkar, Jack C. Y. Cheng Asynchronous neuroosseous growth in adolescent idiopathic scoliosis-MRI-based research. Pediatr Radiol, 41:1100-1111, 2011.

15.Koleva I., Short Course on Kinesitherapy (for rehabilitation therapists). 2nd Complete and Revised Edition. Textbook for rehabilitation therapists from the first year of Medical College at Medical University Sofia. - Sofia: "SIMEL, 168 p. ", 2009.

16. Kraijikova L., Manual methods for mobilization in musculoskeletal dysfunctions in the spine, Monograph, Sofia, p.177, 2011.

17.Chiwaridzo Matthew, Nirmala Naidoo2Functional consequences and health-care seeking behaviour for recurrent non-specific low back pain in Zimbabwean adolescents: a cross-sectional study. Springer-Verlag Berlin Heidelberg. Eur Spine J, 25:643-650, 2016.

18.Kenyon L., M. Blackinton .Applying Motor-Control Theory to Physical Therapy
PASKALEVA R., et al. Practice: A Case Report. Journal ListPhysiother Canv.63(3); Summer 2011.

19.Vacheva D. Types of grip and their testing for various injuries and diseases of the hand. - Neurorehabilitation, Volume 3, 1-2, p.26-31, 2009.

20.Dimitrova E., Muscle Relaxation and Stretching in Manual Therapy, NSA PRESS, Sofia, p.223, 2008.

21.Platikanova M. Illness in children and students from Stara Zagora region. Varna Medical Forum; 4 (3): pp.252-256, 2015.

22.Platikanova M., V. Karaboyeva. Some indicators for physical development of children and students from Stara Zagora region. Varna Medical Forum; 4 (3): pp.257-261, 2015.

23.Platikanova M., V. Karaboyeva, S. Naneva. The state of the sports facilities in the schools in Stara Zagora - a prerequisite for good health. Varna Medical Forum; 4 (3): pp.262-266, 2015.

24.Zadeh JR, Gleiber MA. Adolescent Idiopathic Scoliosis: An in Depth Analysis and Historical Review. MOJ Orthop Rheumatol 3(4): 00105, 2015.

25.Konieczny M. R., H. Senyurt, R. Krauspe. Epidemiology of adolescent idiopathic scoliosis. J Child Orthop, 7:3-9, 2013.

26. Vacheva D. Effectivness evaluation of training program content for the discipline "Basics of functionality evaluation in medical rehabilitation and ergotherapy". The unity of science, Febuary, 65-67, 2016. 